\title{
Effect of Phosphorylation and Copper(II) or Iron(II) Ions Enrichment on Some Physicochemical Properties of Spelt Starch
}

\author{
Jacek Rożnowski ${ }^{1 *}$, Teresa Fortuna ${ }^{1}$, Katarzyna Nowak ${ }^{1}$, Edyta Szuba ${ }^{1}$. \\ ${ }^{1}$ Uniwersytet Rolniczy im. Hugona Kołtataja w Krakowie, Departmant of Food Analysis and Evaluation of Food \\ Quality, Krakow, Poland.
}

\begin{abstract}
This paper provides an assessment of the effect of saturation of spelt starch and monostarch phosphate with copper or iron ions on selected physicochemical properties of the resulting modified starches. Native and modified spelt starch samples were analyzed for selected mineral element content using Atomic Absorption Spectroscopy (AAS). Thermodynamic properties were measured using DSC, and pasting properties by RVA. Flow curves of 5\% pastes were plotted and described using the Herschel-Bulkley model. The structure recovery ratio was measured. AAS analysis established the presence of iron(II) and copper(II) ions in the samples of modified starches and that potassium and magnesium ions had leached from them. In comparison to unfortified samples, enriching native starch with copper(II) ions decreases value of all temperatures of phase transformation about 1.3-2.7 ${ }^{\circ} \mathrm{C}$, but in case of monostarch phosphates bigger changes $\left(2.8-3.7^{\circ} \mathrm{C}\right)$ were observed. Fortified native spelt starch with copper(II) ions caused increasing the final viscosity of paste from 362 to $429 \mathrm{mPa} \cdot \mathrm{s}$. However, presence iron(II) ions in samples caused reduced its final viscosity by 170 (spelt starch) and $103 \mathrm{mPa} \cdot \mathrm{s}$ (monostarch phosphate). Furthermore, enriching monostarch phosphate contributed to reduce degree of structure recovery of pastes from $70.9 \%$ to $66.6 \%$ in case of copper(II) ions and to $59.9 \%$ in case of iron(II) ions.
\end{abstract}

Key words: chemically modified starch, enrichment, phosphorylation, spelt starch

\footnotetext{
${ }^{1}$ Authors for correspondence: rrroznow@cyf-kr.edu.pl
} 


\section{INTRODUCTION}

Starch is one of the most widely used ingredients in the food industry, but its range of application extends to other industries, including pharmaceuticals. It is used for thickening, stabilization, texture smoothing, aroma encapsulation and fat substitution as well as affecting the moisture content of a product (Kaur et al. 2012). This polymer is easily modified by physical and chemical treatment, and therefore manufacturers often use starch to adjust the properties of their products. New functional, physical and chemical properties imparted to modified starches have brought new food products onto the market (Hung and Morita 2005). The use of various starch modification methods enables to obtain products with different properties; therefore, selecting the appropriate method of modification starch is a crucial part of the manufacturing process. The use of modified starch in food technology must impart the desired properties to food products, but should not hinder the production process. Consequently, selection of starch should take into account nutritional, sensorial, production, distribution and marketing requirements.

The chemical modification of starch is based on the reactivity of amylase and amylopectin functional groups. For the food industry, starch phosphates are particularly important. They are created by incorporating acid substituents of orthophosphate into the starch. The method of enrichment the acid molecule determines whether a mono- or di-starch phosphate is obtained (Fortuna and Rożnowski 2002).

The food industry approves only of starch phosphates with a low substitution ratio so as not to alter the calcium to phosphorus ratio in food products (Fortuna and Rożnowski 2002). Monostarch phosphates are used as thickening agents in soups, sauces, dressings and, in particular, cold jelly desserts, as well as being ingredients in puddings, thermized cottage cheese, food concentrates, milk shakes and low calorie margarine. EU Commission Regulation 1129/2011 lists starch phosphate as an additive authorized for food use at quantum satis levels.

Corn, wheat, rice and potatoes are the major sources of starch used worldwide, but new sources of starch with new functional properties are constantly being sought. Although spelt starch has been known in the food industry for some time, this species of wheat is experiencing a renaissance. Spelt wheat belongs to the Gramineae Juss family (Campbell 1997); however, there are no definite data on the origins of spelt and there is some uncertainty about its classification. Most sources classify spelt as a subspecies of common wheat, Triticum aestivum, although some regard it as a separate species (Blatter et al. 2003; Campbell 1997; Kohajdová and Karoviĉová 2008). Modern life-styles are altering dietary habits: lack of time and constant hurry have increased the demand for quickly prepared convenience foods which have been heavily processed and frequently decreased of important nutrients. Therefore, the nutritional value of such products is generally lower than that of traditionally prepared meals. These and other factors have led to the growth of vitamin and mineral supplementation in foods (Anonymous 1999; Lozoff et al. 2012; Ma and Betts 2000). In order to meet the growing quality expectations of consumers, new convenient and safe methods of supplying minerals should be developed, not only preserving nutritional qualities but even enhancing them.

Anemia, the result of low levels of hemoglobin in the blood, was the most widespread blood disease at the end of 20th century. Iron deficiency, the main cause, is responsible for $80 \%$ of cases, although, less commonly, vitamin B12 or folic acid deficiency may also be factors. Anemia often affects young people and women in reproductive age. Despite low iron intake in the diet and frequent cases of anemia, iron enrichment of food is limited to a narrow range of products (Cook 1995; Cook 2005; Zimmermann and Hurrell 2007).

Copper is another important microelement. As a component of cofactors, it is involved in oxidation and reduction processes, and affects the metabolism of iron and collagen. Infants with low birth weight are the major risk group for copper deficiency. Adults are rarely affected, although it may be triggered by zinc supplementation or high fructose consumption (Anonymous 2010; Festa and Thiele 2011; Hong et al. 2001).

This paper provides an assessment of the effect of the phosphorylation of spelt starch and the enrichment of spelt starch and monostarch phosphate with copper(II) and iron(II) ions on selected physical and chemical properties of the resulting starch samples. It also evaluates the level of ion incorporation during the modification treatment and seeks to ascertain whether changes in the properties of modified starches are significant when compared with natural starch. 


\section{MATERIAL AND METHODS}

The research material was spelt starch, extracted from spelt flour (ECCO 700) under laboratory conditions. The flour, milled in 2010, was obtained from Młyn Gospodarczy, Radzyń Podlaski, Poland

\section{Spelt starch preparation}

Spelt starch was isolated from spelt flour following the procedure described by Moreira et al. (2012), with minor changes. Spelt flour $(1 \mathrm{~kg})$ was soaked in $500 \mathrm{~mL}$ of distilled water at room temperature. The suspension was placed on a nylon sieve (100 $\mu \mathrm{m}$ mesh) and the kneaded dough was rinsed with distilled water. The dough was continuously kneaded and rinsed until pure gluten was obtained. The resulting starch milk was poured into $200 \mathrm{~mL}$ plastic centrifuge vessels and centrifuged for 20 minutes at $4000 \mathrm{rpm}$. After spinning, the supernatant was poured off and the layer of impurities was removed with a spatula. A new portion of starch milk was added and the whole was mixed and centrifuged again. The process was repeated three times, after which the supernatant and impurities were removed, distilled water was added, and the whole was mixed and centrifuged again. After the final spinning, the supernatant was poured off, the impurities was removed and the sediment was transferred to plastic dishes, ground and air-dried at room temperature while being constantly stirred. After drying, the polymer was ground in a Retsch RM-200 mortar and filtered through a $125 \mu \mathrm{m}$ Retsch AS-200 sieve. The obtained spelt starch contained $20.89 \%$ amylose, $0.27 \%$ protein and $9.4 \%$ moisture.

\section{Phosphorylation}

The spelt starch was used to make monostarch phosphates using Neukom's modified method (Richter et al. 1968). Spelt starch (216 g d.m.) was rinsed with water in a $1 \mathrm{G}$ Schott funnel, and then transferred to a vessel, to which $12.28 \mathrm{~g}$ of sodium dihydrophosphate and $7.81 \mathrm{~g}$ of sodium hydrophosphate diluted in a small amount of water were added. The mixture was stirred for 5 minutes. The resulting starch suspension was dried in Petri dishes at room temperature to a moisture content of about $10 \%$. The dried mixture was ground in a porcelain mortar, and then heated for 1 hour in an Erlenmeyer flask over an oil bath at $160^{\circ} \mathrm{C}$ while being constantly stirred. The cooled powder was added to $150 \mathrm{~cm}^{3}$ of $60 \%$ ethanol, and filtered through a $1 \mathrm{G}$ Schott funnel. This process was repeated four times with $96 \%$ ethanol used for the last run. The resulting sample was transferred to Petri dishes and dried at room temperature to air humidity. After drying, the resulting monostarch phosphates were ground in a Retsch, RM-200 mortar and filtered through a $125 \mu \mathrm{m}$ Retsch AS-200 sieve.

Both the spelt starch and the spelt monostarch phosphate were subjected to saturation with copper(II) and iron(II) ions.

\section{Copper(II) and Iron(II) ions saturation}

The native spelt starch and the spelt monostarch phosphate were enrichment with copper(II) ions according Przetaczek-Rożnowska et al. (2012) method and iron(II) ions according procedure described by Rożnowski et al. (2014). The starch sample $(100 \mathrm{~g})$ were stirred for 5 minutes with deionized water $\left(250 \mathrm{~cm}^{3}\right)$ and filtered. Next, the starch was transferred to a G3 Schott funnel and stirred for 5 minutes at $330 \mathrm{rpm}$ with $200 \mathrm{~cm}^{3}$ of salts solution $\left(39.6 \mathrm{~g} \mathrm{CuSO}_{4} \cdot 5 \mathrm{H}_{2} \mathrm{O}\right.$ in $1 \mathrm{dm}^{3}$ of water or $18.31 \mathrm{~g} \mathrm{FeSO}_{4} \cdot 5 \mathrm{H}_{2} \mathrm{O}$ in $1 \mathrm{dm}^{3}$ of water). The procedure was repeated twice. After completion, the sample was rinsed in deionized water until sulfide ions were no longer present (lack of white sediment during reaction with $\mathrm{BaCl}_{2}$ ). The resulting starch was air dried on paper tissue to a moisture content of $10 \%$, then ground in a Retsch RM-200 grinder. After grinding, the samples were filtered through a $125 \mu \mathrm{m}$ Retsch AS-200 sieve.

\section{Determination of mineral content}

Spelt starch, monostarch phosphate and samples enriched with minerals were analyzed for potassium, magnesium, copper and iron content by AAS. The measurements were performed using an atomic absorption spectrometer (Avanta Sigma, GBC, Australia) following Antanasopoulos' (2004) method, selecting wavelength $\lambda$ for each of the elements: $\mathrm{K}-769,9 \mathrm{~nm}, \mathrm{Mg}-285,2 \mathrm{~nm}, \mathrm{Ca}-422,7$ $\mathrm{nm}$ and $\mathrm{Fe}-248,3 \mathrm{~nm}$. Limit of detection (LOD) and limit of quantification (LOQ) were determined by measuring absorbance according to Doerffel (1989).

The content of phosphorus was measured according to ISO 3946:1982.

\section{Color analysis}

The color of the starches under investigation was determined using an X-Rite Color i5 
Rożnowski, Jacek et al.

spectrophotometer. $\mathrm{D}_{65}$ illuminants were applied for the $\mathrm{d} / 8$ geometry and $10 \mathrm{~mm}$ measurement slot. Color was determined in specular excluded mode for CIE 1964 additional observer. The CIE L*, a*, $\mathrm{b}^{*}$ coordinates were determined using X-Rite Color Master SW, while the saturation values $\left(\mathrm{C}^{*}\right)$ was computed according to Yam and Papadakis (2004).

\section{Thermodynamic properties of starch gelatinization}

The thermodynamic parameters of gelatinization were measured using a Netzsch DSC 204 F1 Phoenix differential scanning calorimeter (Netzsch $\mathrm{GmbH}$, Germany). In order to determine the thermal properties of the samples, $3.5 \mathrm{mg}$ of sample and $10.5 \mathrm{mg}$ water were stored at room temperature in calorimetry pans, sealed hermetically and stored for 24 hours at room temperature. The temperature of the samples was increased from 20 to $110^{\circ} \mathrm{C}$ at a rate of $10^{\circ} \mathrm{C} / \mathrm{min}$. After analysis, the pans were stored at $4^{\circ} \mathrm{C}$ for 7 days, after which the thermodynamic properties of retrogradation were determined in a similar manner. An empty calorimetry pan was used as the reference. The resulting thermograms enabled the temperatures specific for gaseous transformations to be determined.

\section{Pasting properties (RVA)}

Pasting properties were determined using a Rapid Visco Analyzer (RVA). A 5\% suspension of starch in distilled water was prepared in metal vessels. The RVA procedure was conducted as follows: samples were stirred at $960 \mathrm{rpm}$ for 1 minute at $50^{\circ} \mathrm{C}$, then the starch suspension was stirred at the same temperature for 1 minute with a speed $160 \mathrm{rpm}$. Next, the samples was heated from $50^{\circ}$ to $95^{\circ} \mathrm{C}$ with a heating rate $4.5^{\circ} \mathrm{C} / \mathrm{min}$. The temperature $95^{\circ} \mathrm{C}$ was maintained for 5 minutes. Then the sample was cooled down to $50^{\circ} \mathrm{C}$ in the space of $10 \mathrm{~min}$ and kept at that temperature for $5 \mathrm{~min}$, during which time was the function of viscosity against time constantly measured.

\section{Flow curves}

The flow curves of monostarch phosphate and spelt starch pastes as well as samples enriched with copper(II) or iron(II) ions were charted using a Rheolab MC1 rotational rheometer (Physica Meßtechnic GmbH, Germany), with Z3 DIN coaxial cylinders $(25.00 \mathrm{~mm}$ internal, $27.12 \mathrm{~mm}$ external diameter) as the measurement system. The rheometer and thermostat (Viscotherm2) were controlled by US 200 software (Physica Me $\beta$ technic GmbH, Germany). To determine flow curves, $5 \% \mathrm{w} / \mathrm{w}$ pastes of starch in distilled water were prepared. These samples were stirred at 300 rpm for 15 minutes at room temperature. Next, the vessel was heated for 30 minutes in a $95^{\circ} \mathrm{C} \pm 1^{\circ} \mathrm{C}$ water bath, constantly stirred at $300 \mathrm{rpm}$. The paste was then immediately placed in the rheometer measurement vessel, and kept for 10 minutes at a constant temperature of $50^{\circ} \mathrm{C} \pm 0.5^{\circ} \mathrm{C}$.

The flow curves were charted for the increasing shearing rate in the range of $1-500 \mathrm{~s}^{-1}$, over 3 minutes, for the constant $500 \mathrm{~s}^{-1}$ shear rate over 2 minutes, for the diminishing shearing rate in the range of 500-1 s $\mathrm{s}^{-1}$, over 3 minutes.

The curves were described according to the Herschel-Bulkley rheology model

$$
\tau=\tau_{0}+K(\dot{\gamma})^{n}
$$

where: $\tau$ : shear stress $(\mathrm{Pa}), \tau_{0}$ : the yield strength

$(\mathrm{Pa}), \mathrm{K}$ : consistency index $\left(\mathrm{Pa} \cdot \mathrm{s}^{\mathrm{n}}\right), \quad \dot{\gamma}$ : shear rate

$\left(\mathrm{s}^{-1}\right), \mathrm{n}$ : flow index. The parameters were

computed with the use of the US 200 SW.

\section{Degree of structure recovery of starch paste Time - test}

The recovery ratio of 5\% starch paste was measured in the manner described for determining flow curves. The samples were kept in the measurement vessel of the rotational rheometer for 10 minutes in $50^{\circ} \mathrm{C} \pm 0.5^{\circ} \mathrm{C}$ and then analyzed using the modified Mezger (2002) and Pająk et al. (2012) procedure, with constant shear rates of: $1 \mathrm{~s}^{-1}$, for 3 minutes; 500 $\mathrm{s}^{-1}$, for 3 minutes; and $1 \mathrm{~s}^{-1}$, for 10 minutes.

The ratio of structure reconstruction $(\mathrm{R})$ was computed as percentage of apparent viscosity $\left(\eta_{2}\right)$ obtained during the first minute of the third step based on the apparent viscosity value $\left(\eta_{1}\right)$ determined in the first 3 minutes of measurement:

$$
R=\left(\eta_{2} / \eta_{1}\right) 100 \%
$$

\section{Statistical analysis}

All calculations and charts were carried out using Excel 2007. All treatments were repeated three times. The results were tested for $\alpha=0.05$ (Tukey's HSD test) using Statistica 8.0 SW to identify homogeneous groups. 


\section{RESULTS AND DISCUSSION}

\section{Mineral components of native and modified starch}

The analyses indicated that both phosphorylation and the enrichment with copper(II) or iron(II) ions of spelt starch and the resulting monostarch phosphates lead to decrease of potassium and magnesium naturally present in the starch (Table 1). Magnesium, although being the least abundant of the minerals present in the starch and monostarch phosphate examined in this investigation, was the most resistant to leaching. Similar results have been observed in the saturation of potato and corn starches (Rożnowski et al. 2014). The fact that the leaching rate of calcium and magnesium from the starch and monostarch phosphate was lower than that of potassium demonstrates that bivalent ions are much more strongly bound by such features as "calcium bridges" (Pałasiński, 1968), which resist leaching much more effectively than univalent ions. Phosphorus is an important mineral component in starch grains; its content varies depending on the plant source (Swinkels 1985; Singh et al. 2003). Saturation with minerals resulted in a statically significant loss of phosphorus (Table 1). Rożnowski et al. (2014) also reported leached phosphorus from potato starch granules during modification with $\mathrm{FeSO}_{4}$, whereas phosphorus content in corn starch after rinsing with ions solutions showed no statistically significant changes relative to control corn starch.

Table 1 - Mineral content in the starch samples examined (mg/100 g dry matter)

\begin{tabular}{lllllll}
\hline Samples & $\mathrm{K}$ & $\mathrm{Mg}$ & $\mathrm{Ca}$ & $\mathrm{Cu}$ & $\mathrm{Fe}$ & $\mathrm{P}$ \\
\hline ss & $22.32 \pm 0.13$ & $4.56 \pm 0.27$ & $8.15 \pm 0.19$ & $\mathrm{nd}$ & $\mathrm{nd}$ & $61.97 \pm 0.79^{\mathrm{d}}$ \\
ss_Cu & nd & nd & nd & $11.17 \pm 0.32$ & nd & $37.48 \pm 0.54^{\mathrm{f}}$ \\
ss_Fe & nd & $0.67 \pm 0.37$ & nd & nd & $29.93 \pm 0.75$ & $51.67 \pm 0.64^{\mathrm{e}}$ \\
\hline LOD & 1.9 & 0.3 & 0.6 & 0.3 & 1.00 & - \\
LOQ & 3.3 & 0.5 & 1.2 & 0.5 & 2.01 & - \\
& & & & & & \\
ps & $15.2 \pm 0.10$ & $3.97 \pm 0.55$ & $9.93 \pm 0.06$ & nd & nd & $1011.56 \pm 1.02^{\mathrm{a}}$ \\
ps_Cu & nd & nq & $3.43 \pm 0.06$ & $503.6 \pm 4.01$ & nd & $211.15 \pm 0.47^{\mathrm{c}}$ \\
ps_Fe & nq & $3.57 \pm 0.15$ & $1.20 \pm 0.10$ & nd & $392.63 \pm 2.21$ & $215.10 \pm 0.68^{\mathrm{b}}$ \\
\hline LOD & 0.6 & 0.1 & 0.5 & 0.3 & 7.7 & - \\
LOQ & 1.2 & 0.2 & 1.1 & 0.5 & 15.3 & - \\
\hline
\end{tabular}

ss = spelt starch (native); ss_Cu = spelt starch enriched with copper(II) ions; ss_Fe = spelt starch enriched with iron(II) ions; ps = spelt monostarch phosphate; ps_Cu = spelt monostarch phosphate enriched with copper(II) ions; ps_Fe = spelt monostarch phosphate enriched with iron(II) ions; nd = below Limit of Detection (LOD); nq = between Limit of Detection (LOD) and Limit of Quantification (LOQ).

followed by the same letter in a column are not significantly different at $\alpha=0.05$ (Tukey's HSD test). Each value is expressed as the mean \pm standard deviation of triplicate measurements.

The phosphorus present in starch affects its ion exchange properties (Richter 1968; Jane et al. 1996; Lin and Czuchajowska 1998; Rożnowski et al. 2014), which was confirmed in the present study: during saturation, spelt monostarch phosphate absorbed ten times more iron(II) ions than natural starch, and about forty five times more copper (Table 1). Natural starch absorbed iron better than copper, while the monostarch phosphate absorbed copper more effectively (Table 1). This shows that the effectiveness of mineral enrichment depends on both the nature of the starch and the mineral being enriched.

\section{Color analysis}

The color parameters were analyzed in order to investigate the influence of presence of copper(II) or iron(II) ions on color of modified starches, as a first factor in sensorial impression. The derived color parameters indicate that both enrichment of spelt starch and its phosphorylation affect color (Fig. 1). All colors parameter were compared to those in the unfortified starch samples. Mineral saturation decreased the lightness of the natural starch from 97.46 to 94.05 for starch enriched with copper(II) and to 92.01 for native starch fortified with iron(II) ions. As well the monostarch phosphate had distinctly lower $\mathrm{L}^{*}$ values (by 12 units) than native spelt starch, which shows that starch modification, whatever the type, reduces lightness. Similar results have been observed in the 
saturation of potato and corn monostarch phosphate (Rożnowski et al. 2015) and was also reported for phosphorylated spelt starch obtained during heating at 130 or $145^{\circ} \mathrm{C}$ for 2 or 3 hours (Rożnowski et al. 2016a) or phosphorylated starch obtained from pumpkin starch during heating at $145^{\circ}$ (Rożnowski et al. 2016b).
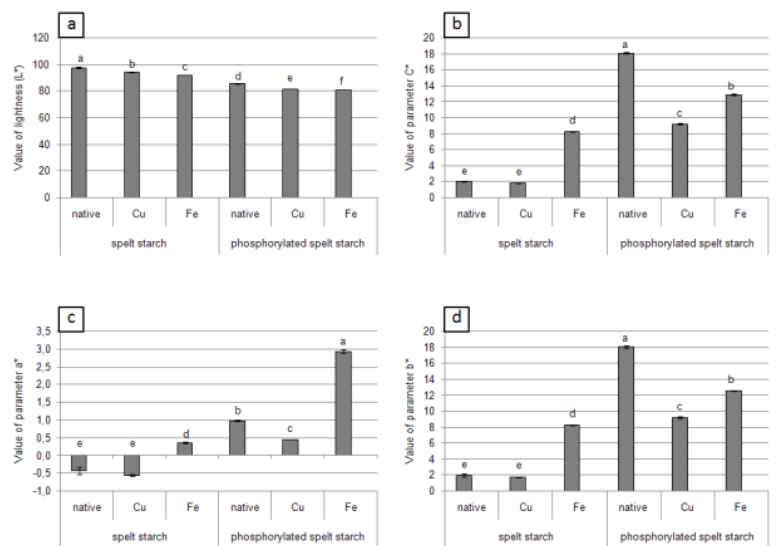

Figure 1- Value of color parameters of native and phosphorylated spelt starch and enriched with iron or copper ions (a) value of Lightness; (b) chroma of the color $\mathrm{c}^{*}$; (c) value of parameter $\mathrm{a}^{*}$; (d) value of parameter $b^{*}$.

Values expressed are mean \pm standard error $(\mathrm{n}=3)$. Values followed by the same letter in a figure are not significantly different at $\alpha=0.05$.

Values of $\mathrm{a}^{*}$ or $\mathrm{b}^{*}$ parameters examined for saturated sample with copper(II) ions were lower than values obtained for unfortified samples. On the other hand, the native spelt starch and monostarch phosphate enriched with iron(II) ions were characterized by 3 times higher value of $a^{*}$ parameter. Our research confirmed observation reported for phosphorylated potato or corn starch saturated with copper(II) or iron(II) ions (Rożnowski et al. 2015). In case the $b^{*}$ parameter there did not observed constant relationship. The value of this parameter for native starch saturated with iron(II) ions was over 4 times higher than value obtained for native spelt starch, meantime the monostarch phosphate fortified with iron(II) ions was characterized by lower value of $b^{*}$ parameter
(12.54) than unfortified monostarch phosphate (18.03). Our research did not confirm observation reported for phosphorylated potato or corn starch (Rożnowski et al. 2015) were enrichment phosphorylated corn or potato starch with iron(II) ions caused increase value of $b^{*}$ parameter.

Unenriched monostarch phosphate had higher color saturation $\left(\mathrm{C}^{*}\right)$ value in comparison with native spelt starch. Starch enriched with copper(II) had the lowest saturation (1.81) what confirmed observation reported for potato or corn phosphorylated starches (Rożnowski et al. 2015).

\section{DSC of the thermodynamic properties}

The value of gelatinization temperatures $\left(T_{o}, T_{p}\right.$ and $\mathrm{T}_{\mathrm{e}}$ ) of analyzed spelt starch were similar to those found for wheat starch by Aggarwal and Dollimore (1998). However, there were lower than those published for wheat starch by Nakazawa and Wang (2003) and higher than those recorded also for wheat starch by Jacobs et al. (1998) or Gunaratne and Corke (2007). The gelatinization temperatures as $T_{0}, T_{p}$ and $T_{e}$ are indicators of the stability of starch granules or the starch crystal structure in water (Aparicio-Saguilan et al. 2005; Lehmann et al. 2002). Morikawa and Nishinari (2000) indicated that starch modification changes gelatinization and reorganizes the structure patterns in starch. Polymer esterification increases the peak temperature $\left(T_{p}\right)$ (Sagar and Merrill 1995; Rajan et al. 2006), which was confirmed in the present work: spelt monostarch phosphate showed markedly higher $T_{p}$ than natural spelt starch (Table 2). This is attributed to alterations of the crystal structure and change of the amorphous areas of starch granules (Tester and Debon 2000). The DSC of monostarch spelt phosphate also showed considerably higher end temperature $\left(\mathrm{T}_{\mathrm{e}}\right)$, both in the initial measurement, and after 7 days' storage (Table 2). The enrichment of copper(II) into native spelt starch and monostarch phosphate and iron(II) ions into spelt starch decreased the $T_{0}, T_{p}$ and $T_{c}$ of gelatinization during the first day. This may indicate structural changes of both the starch and the monostarch phosphate in reaction to mineral incorporation. 
Table 2 - Gelatinization parameters

\begin{tabular}{|c|c|c|c|c|c|c|c|c|}
\hline \multirow{2}{*}{ Samples } & \multicolumn{4}{|c|}{ Gelatinization } & \multicolumn{4}{|c|}{ Retrogradation } \\
\hline & $\mathrm{T}_{\mathrm{o} 1}\left({ }^{\circ} \mathrm{C}\right)$ & $\mathrm{T}_{\mathrm{p} 1}\left({ }^{\circ} \mathrm{C}\right)$ & $\mathrm{T}_{\mathrm{e} 1}\left({ }^{\circ} \mathrm{C}\right)$ & $\Delta \mathrm{H}_{1}(\mathrm{~J} / \mathrm{g})$ & $\mathrm{T}_{\mathrm{o} 2}\left({ }^{\circ} \mathrm{C}\right)$ & $\mathrm{T}_{\mathrm{p} 2}\left({ }^{\circ} \mathrm{C}\right)$ & $\mathrm{T}_{\mathrm{e} 2}\left({ }^{\circ} \mathrm{C}\right)$ & $\Delta \mathrm{H}_{2}(\mathrm{~J} / \mathrm{g})$ \\
\hline ss & $54.2 \pm 0.25^{b}$ & $62.3 \pm 0.12^{\mathrm{c}}$ & $68.8 \pm 0.36^{\mathrm{b}}$ & $6.76 \pm 0.39^{b}$ & $40.7 \pm 0.10^{\mathrm{b}}$ & $51.5 \pm 0.00^{\mathrm{b}}$ & $60.9 \pm 0.65^{c}$ & $3.04 \pm 0.24^{\mathrm{a}}$ \\
\hline ss_Cu & $51.5 \pm 0.15^{\mathrm{c}}$ & $60.1 \pm 0.40^{\mathrm{d}}$ & $67.5 \pm 0.35^{\mathrm{cd}}$ & $7.82 \pm 0.09^{\mathrm{a}}$ & $40.9 \pm 0.40^{b}$ & $51.2 \pm 0.12^{b}$ & $62.0 \pm 0.87^{b c}$ & $2.73 \pm 0.14^{\mathrm{a}}$ \\
\hline ss_Fe & $50.4 \pm 1.69^{c}$ & $60.1 \pm 0.17^{\mathrm{d}}$ & $67.8 \pm 0.32^{c}$ & $6.15 \pm 0.15^{\mathrm{c}}$ & $33.8 \pm 0.82^{c}$ & $51.5 \pm 1.01^{b}$ & $60.9 \pm 1.06^{c}$ & $2.68 \pm 0.40^{\mathrm{a}}$ \\
\hline $\mathrm{ps}^{-}$ & $54.0 \pm 0.10^{b}$ & $63.2 \pm 0.20^{\mathrm{b}}$ & $70.0 \pm 0.12^{\mathrm{a}}$ & $6.47 \pm 0.14^{\mathrm{bc}}$ & $44.1 \pm 0.06^{\mathrm{a}}$ & $54.8 \pm 0.17^{\mathrm{a}}$ & $63.8 \pm 0.23^{\mathrm{ab}}$ & $1.37 \pm 0.06^{\mathrm{bc}}$ \\
\hline ps_Cu & $51.2 \pm 0.12^{\mathrm{c}}$ & $59.5 \pm 0.31^{\mathrm{e}}$ & $66.8 \pm 0.17^{\mathrm{d}}$ & $3.33 \pm 0.06^{\mathrm{e}}$ & $44.3 \pm 0.35^{\mathrm{a}}$ & $54.6 \pm 0.31^{\mathrm{a}}$ & $62.6 \pm 0.21^{\mathrm{bc}}$ & $1.70 \pm 0.10^{\mathrm{b}}$ \\
\hline ps_Fe & $56.5 \pm 0.26^{\mathrm{a}}$ & $64.0 \pm 0.06^{\mathrm{a}}$ & $70.2 \pm 0.15^{\mathrm{a}}$ & $5.07 \pm 0.06^{\mathrm{d}}$ & $44.3 \pm 0.36^{a}$ & $55.5 \pm 0.31^{\mathrm{a}}$ & $64.8 \pm 0.20^{\mathrm{a}}$ & $0.97 \pm 0.10^{\mathrm{c}}$ \\
\hline
\end{tabular}

ss = spelt starch (native); ss_Cu = spelt starch enriched with copper(II) ions; ss_Fe = spelt starch enriched with iron(II) ions; ps = spelt monostarch phosphate; ps_Cu $=$ spelt monostarch phosphate enriched with copper(II) ions; ps_Fe $=$ spelt monostarch phosphate enriched with iron(II) ions; $\mathrm{T}_{\mathrm{o}}=$ onset temperature; $\mathrm{T}_{\mathrm{p}}=$ peak temperature; $\mathrm{T}_{\mathrm{e}}=$ final temperature; $\Delta \mathrm{H}=\mathrm{enthalpy}$

Values followed by the same letter in a column are not significantly different at $\alpha=0.05$ (Tukey's HSD test). Each value is expressed as the mean \pm standard deviation of triplicate measurements.

All of the samples examined, monostarch phosphate enriched with copper(II) ions showed the lowest value of gelatinization parameters (Table 2). This may indicate that the initial structure is deformed to varying degrees depending on the mineral used in modification. Moreover, copper(II) and iron(II) enrichment led to changes in enthalpy values (Table 2). Gelatinization enthalpy reflects the energy necessary for disrupting apart starch granules (Liu et al. 1999). Copper(II) enriched spelt starch required greater energy to disrupt apart starch granules on the first day of thermal analysis, while the presence of iron(II) weakened the bonds compared with the natural starch (Table 2). In the second stage of DSC analysis, however, there were no significant differences in enthalpy values or other process parameters between natural and Copper(II) enrichment resulted in increased values of peak viscosity (PV), trough (TV), final viscosity $(\mathrm{FV})$ and setback (SB) compared with the natural starch; this was in contrast to the corresponding values obtained following iron(II) enrichment, which were lower than those for natural starch (Table 3). On the other hand, the phosphorylation of spelt starch led to a decrease in the trough, final viscosity and setback values, while monostarch phosphate enrichment with copper(II) or iron(II) further decreased these values. enriched spelt starch or between the natural and enriched spelt monostarch phosphate.

\section{Pasting properties determined by RVA}

An examination of the pasting properties showed that enriching spelt starch with copper(II) or iron(II) ions did not affect the pasting temperature of the samples analyzed. However, phosphorylation considerably lowered the pasting temperature, and copper-enriched spelt monostarch phosphate had the lowest pasting temperature of all the starches investigated (Table 3). A change of certain pasting properties of examined starches, including pasting temperature (Table 3) may be affected by changes in the crystal structure during process of starch modification as Lewandowicz et al. (2000) reported for wheat and corn starches.

The phosphorus present in grain starches has been found to affect the retrogradation and viscosity of starch pastes (Jane et al. 1996; Lin and Czuchajowska 1998). However, our research did not confirm this, which suggests that pasting parameters depend not only on the presence of phosphorus, but also on the mineral enriched in the starch.

Table 3 - Pasting properties

\begin{tabular}{llllllc}
\hline Samples & $\mathrm{T}_{\mathrm{g}}\left({ }^{\circ} \mathrm{C}\right)$ & $\mathrm{PV}(\mathrm{mPas})$ & $\mathrm{TV}(\mathrm{mPas})$ & $\mathrm{BD}(\mathrm{mPas})$ & $\mathrm{FV}(\mathrm{mPas})$ & $\mathrm{SB}(\mathrm{mPas})$ \\
\hline ss & $87.1 \pm 1.69^{\mathrm{a}}$ & $205 \pm 9^{\mathrm{c}}$ & $190 \pm 10^{\mathrm{b}}$ & $232 \pm 20^{\mathrm{a}}$ & $362 \pm 18^{\mathrm{b}}$ & $366 \pm 19^{\mathrm{b}}$ \\
ss_Cu & $85.2 \pm 0.18^{\mathrm{a}}$ & $332 \pm 1^{\mathrm{a}}$ & $226 \pm 2^{\mathrm{a}}$ & $307 \pm 2^{\mathrm{a}}$ & $429 \pm 1^{\mathrm{a}}$ & $404 \pm 1^{\mathrm{a}}$ \\
ss_Fe & $85.9 \pm 0.01^{\mathrm{a}}$ & $153 \pm 1^{\mathrm{d}}$ & $69 \pm 1^{\mathrm{c}}$ & $137 \pm 2^{\mathrm{a}}$ & $192 \pm 4^{\mathrm{d}}$ & $175 \pm 4^{\mathrm{c}}$ \\
ps & $78.1 \pm 0.42^{\mathrm{b}}$ & $235 \pm 4^{\mathrm{b}}$ & $82 \pm 1^{\mathrm{c}}$ & $153 \pm 4^{\mathrm{a}}$ & $228 \pm 2^{\mathrm{c}}$ & $146 \pm 2^{\mathrm{c}}$ \\
ps_Cu & $65.2 \pm 0.85^{\mathrm{c}}$ & $312 \pm 8^{\mathrm{a}}$ & $85 \pm 2^{\mathrm{c}}$ & $228 \pm 14^{\mathrm{a}}$ & $182 \pm 4^{\mathrm{d}}$ & $97 \pm 1^{\mathrm{d}}$ \\
ps_Fe & $79.8 \pm 0.64^{\mathrm{b}}$ & $216 \pm 12^{\mathrm{bc}}$ & $35 \pm 0^{\mathrm{d}}$ & $292 \pm 6^{\mathrm{a}}$ & $125 \pm 3^{\mathrm{e}}$ & $90 \pm 3^{\mathrm{d}}$ \\
\hline
\end{tabular}

ss = spelt starch (native); ss_Cu = spelt starch enriched with copper(II) ions; ss_Fe = spelt starch enriched with iron(II) ions; ps = spelt monostarch phosphate; ps_Cu = spelt monostarch phosphate enriched with copper(II) ions; ps_Fe = spelt monostarch phosphate enriched with iron(II) ions; $\mathrm{T}_{\mathrm{g}}=$ pasting temperature; $\mathrm{PV}=$ peak viscosity; $\mathrm{TV}=$ trough; $\mathrm{BD}=$ breakdown; $\mathrm{FV}=$ final viscosity; $\mathrm{SB}=$ setback. 
Rożnowski, Jacek et al.

Values followed by the same letter in a column are not significantly different at $\alpha=0.05$ (Tukey's HSD test). Each value is expressed as the mean \pm standard deviation of triplicate measurements.

Flow curves and structure recovery of starch paste

The flow curves of $5 \%$ pastes of starch and the resulting monostarch phosphate, as well as of samples enriched with copper(II) and iron(II), are shown in Figure 2, while the Herschel-Bulkley parameters describing the curves are shown in Table 4.
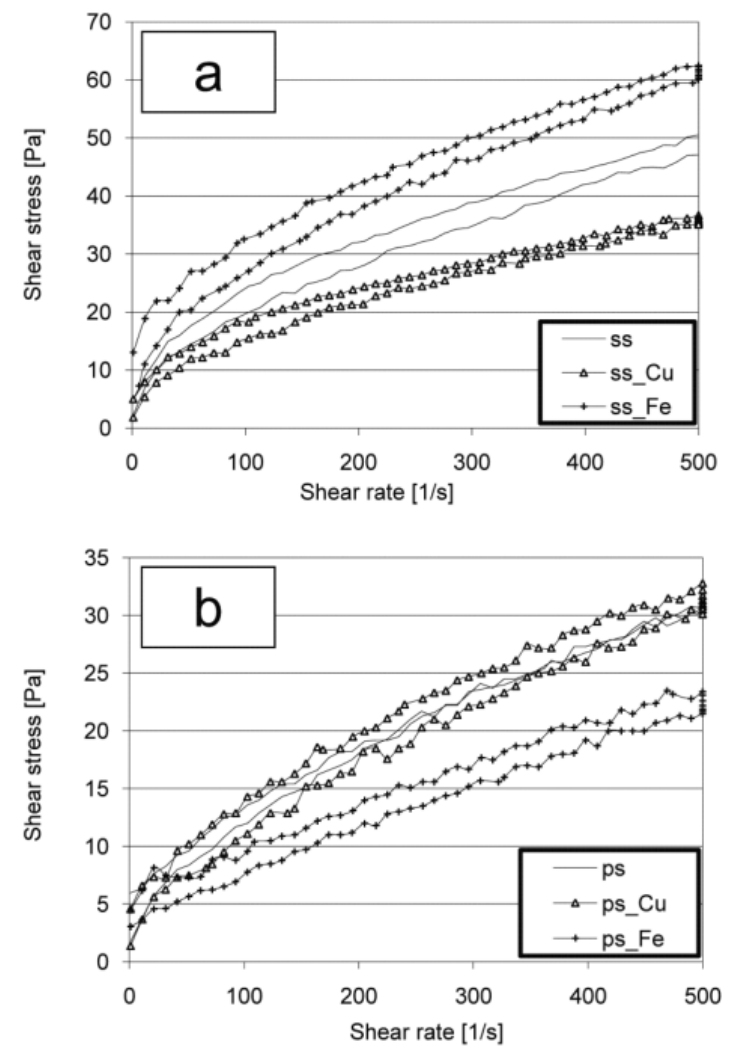

Figure 2 - Flow curves of 5\% pastes (a) ss = native spelt starch; ss_Cu = spelt starch enriched with copper ions; ss_Fe $=$ spelt starch enriched with iron ions; $(b)$ ps = spelt monostarch phosphate; $p s \_C u=$ spelt monostarch phosphate enriched with copper ions; ps_Fe = spelt monostarch phosphate enriched with iron ions.

Table 4 - Herschel-Bulkley parameters for 5\% pastes and structure recovery (R\%) of starch paste

\begin{tabular}{|c|c|c|c|c|c|}
\hline \multirow{2}{*}{ Samples } & \multicolumn{4}{|c|}{ Herschel-Bulkley parameters } & \multirow{2}{*}{$\begin{array}{l}\text { Recovery } \\
(\%)\end{array}$} \\
\hline & $\tau_{0}(\mathrm{~Pa})$ & $\mathrm{K}\left(\mathrm{Pa} \cdot \mathrm{s}^{\mathrm{n}}\right)$ & $\mathrm{n}(-)$ & $\mathrm{R}^{2}$ & \\
\hline SS & $4.38 \pm 1.0^{\mathrm{a}}$ & $1.06 \pm 0.11^{\mathrm{b}}$ & $0.60 \pm 0.04^{b}$ & 0.9994 & $73.3 \pm 3.4^{\mathrm{a}}$ \\
\hline ss_Cu & $3.17 \pm 0.4^{\mathrm{a}}$ & $1.52 \pm 0.08^{\mathrm{a}}$ & $0.49 \pm 0.01^{b}$ & 0.9987 & $74.9 \pm 4.1^{\mathrm{a}}$ \\
\hline ss_Fe & $4.19 \pm 1.2^{\mathrm{a}}$ & $2.60 \pm 0.75^{\mathrm{a}}$ & $0.51 \pm 0.03^{b}$ & 0.9845 & $73.2 \pm 1.1^{\mathrm{a}}$ \\
\hline $\mathrm{ps}^{-}$ & $4.03 \pm 0.3^{\mathrm{a}}$ & $0.43 \pm 0.03^{c}$ & $0.67 \pm 0.00^{\mathrm{ab}}$ & 0.9991 & $70.9 \pm 9.0^{\mathrm{a}}$ \\
\hline ps_Cu & $3.73 \pm 0.5^{\mathrm{a}}$ & $0.51 \pm 0.15^{\mathrm{c}}$ & $0.66 \pm 0.05^{\mathrm{ab}}$ & 0.9986 & $66.6 \pm 2.7^{\mathrm{b}}$ \\
\hline ps_Fe & $4.30 \pm 1.0^{\mathrm{a}}$ & $0.34 \pm 0.06^{\mathrm{c}}$ & $0.79 \pm 0.09^{\mathrm{a}}$ & 0.9968 & $59.9 \pm 2.3^{b}$ \\
\hline
\end{tabular}

ss = spelt starch (native); ss_Cu = spelt starch enriched with copper(II) ions; ss_Fe = spelt starch enriched with iron(II) ions; ps = spelt monostarch phosphate; ps_Cu = spelt monostarch phosphate enriched with copper(II) ions; ps_Fe = spelt monostarch phosphate enriched with iron(II) ions; $\tau_{0}=$ shear stress; $\mathrm{K}=$ consistency index; $\mathrm{n}=$ flow index;

Values followed by the same letter in a column are not significantly different at $\alpha=0.05$ (Tukey's HSD test). Each value is expressed as the mean \pm standard deviation of triplicate measurements. 
The rheological measurements indicate that over the range of the shear rates applied, starches behaved as non-Newtonian shear-thinning fluids that are close to the yield strength (Fig. 2, Table 4). The shear stress of the 5\% pastes was affected over the entire range of measurement by both the enriched mineral and the chemical modification (Fig. 2). Enrichment native spelt starch with copper(II) contributed to a downshifting of the flow curves, while iron(II) caused an increase in the shear stress. Spelt monostarch phosphates behaved differently. The presence of iron(II) ions led to a decrease in shear stress over the entire range of measurement, while copper(II) ions did not affect the shear stress compared with the pure monostarch phosphates. Similar correlations have been reported with respect to natural potato and corn starches enriched with iron (Rożnowski et al. 2014); for any given shear rate, enriched pastes had much lower shear stress than natural starch pastes.

Neither phosphorylation nor mineral enrichment affected the flow index (n) (Table 4). Rożnowski et al. (2014) reported otherwise, finding that the enrichment of potato starch with iron considerably lowered the flow index, while similar treatment of corn starch increased this value. This shows that plant origin affects the rheology of enriched samples. It is probable that origin of starch determine how the incorporated minerals are bound, thus also affecting the rheology of the samples. This is confirmed by the neutral impact of phosphorylation and copper(II) or iron(II) enrichment on the yield strength $\left(\tau_{0}\right)$, (Table 4$)$, and the strong impact on this parameter of iron enrichment in potato and corn starch.

Spelt starch saturated with copper(II) or iron(II) had considerably higher values for the consistency index $(\mathrm{K})$, indicating that the viscosity of the enriched pastes was considerably higher than that of the natural starch pastes (Table 4).

The native spelt starch enriched with ions did not indicate the difference in structure recovery of starch pastes compared with native spelt starch paste without ions (Table 4). Research carried out on the enrichment of iron(II) in potato and corn starch (Rożnowski et al. 2014) showed a considerable weakening of structure recovery. The presumption is that the ions incorporated in the starch bind differently in starches extracted from different plants, thus enabling new intermolecular bonds to be created in spelt starch but not in potato and corn starch. However, the combination of modification (esterification and enrichment with ions) contributed to weakening of structure recovery.

\section{CONCLUSIONS}

Natural spelt starch as well as spelt monostarch phosphate effectively absorbed iron(II) and copper(II) ions and can be used as carriers in mineral supplementation. However, the degree of mineral saturation of spelt starch or monostarch phosphate depends on both the type of the starch and the mineral incorporated in the polymer. Chemical modification of starch, both by phosphorylation and enrichment, leads to decrease of elements naturally present in this starch, including phosphorus, potassium and magnesium. DSC thermal analyses of gelatinization showed that starch enrichment had a significant effect on gelatinization parameters. The extent of the changes depended on the type of starch and the mineral enriched. The pasting properties showed that the presence of iron decreases the final viscosity of the pastes, while copper(II) increases the peak viscosity of both the natural starch and the spelt monostarch phosphate. The extent of rheological changes in spelt starch and spelt monostarch phosphate was affected by saturation with minerals. The presence of iron(II) and copper(II) ions in spelt starch pastes considerably increased the consistency index values, while the incorporation of iron(II) and copper(II) ions in the monostarch phosphate led to a decrease in the structure recovery index after the preset shear rate was decreased.

\section{REFERENCES}

Aggarwal P, Dollimore D. A thermal analysis investigation of partially hydrolyzed starch. Thermochim Acta. 1998; 319: 17-25. http://dx.doi.org/10.1016/S0040-6031(98)00355-4

Anonymous. American Academy of Pediatrics, Committee on Nutrition. Iron fortification of infant formulas. Pediatrics, 1999; 104: 119-123.

Anonymous. The Micronutrient Initiative. Iron program. 2010. [Internet]. [cited 2015 Nov. 25]; Available from: http://www.micronutrient.org/english/view.asp? $\mathrm{x}=5$ $\underline{79}$.

Antanasopoulos N. Flame methods manual for atomic absorption. GBC Scientific Equipment PTY LTD; 2004.

Aparicio-Saguilan A, Flores-Huicochea E, Tovar J, Garcia-Suarez F, Gutierrez-Meraz F, Bello-Perez LA. Resistant starch-rich powders prepared by 
Rożnowski, Jacek et al.

autoclaving of native and lintnerized banana starch: Partial characterization. Starch-Starke. 2005; 57: 405-412. http://dx.doi.org/10.1002/star.200400386

Blatter R, Jacomet S, Schlumbaum A. About the origin of European spelt (Triticum spelta L.): allelic differentiation of the HMW Glutenin B1-1 and A1-2 subunit genes. Springer-Verlag. Theor Appl Genet. 2003; 2(108): 360-367. DOI: 10.1007/s00122-0031441-7

Campbell K. Spelt: agronomy, genetics, and breeding. In:. Plant Breeding Reviews John Wiley \& Sons, Inc; 1997. Vol. 15, p.188-213.

Cook JD. Iron supplementation: is less or better? The Lancet. $\quad 1995 ; \quad 346: \quad 587$. http://dx.doi.org/10.1016/S0140-6736(95)91430-7

Cook JD. Diagnosis and management of iron-deficiency anemia. Best Pract Res Cl Ha. 2005; 18(2): 319-332. http://dx.doi.org/10.1016/j.beha.2004.08.022

Doerffel K. Statistik in der analytischen Chemie. VEB Deutscher Verlag für Grundstoffindustrie. Leipzig; 1989.

Festa RA, Thiele DJ. Copper: an essential metal in biology. Curr Biol. 2011; 21: R877-R883. http://dx.doi.org/10.1016/j.cub.2011.09.040

Fortuna T, Rożnowski J. Chemical modified starches properties and applications. Zywn-Nauk Technol Ja. 2002; 31(2): 16-29. Polish

Gunaratne A, Corke H. Influence of unmodified and modified cycloheptaamylose (beta-cyclodextrin) on transition parameters of amylose-lipid complex and functional properties of starch. Carbohyd Polym. 2007; 68 :

226-234.

http://dx.doi.org/10.1016/j.carbpol.2006.12.017

Hong JH, Duncan SE, Dietrich AM. Effect of copper speciation at different $\mathrm{pH}$ on temporal sensory attributes of copper. Food Qual Prefer. 2001; 21(1): 132-139. http://dx.doi.org/10.1016/j.foodqual.2009.08.010

Hung PV, Morita N. Physicochemical properties and enzymatic digestibility of starch from edible canna (Canna edulis) grown in Vietnam. Carbohydr Polym. 2005; 61: 314-321. http://dx.doi.org/10.1016/j.carbpol.2005.04.021

ISO 3946:1982 Starches and derived products Determination of total phosphorus content Spectrophotometric method.

Jacobs H, Eerlingen RC, Rouseua N, Colonnab P, Delcour JA. Acid hydrolysis of native and annealed wheat, potato and pea starches-DSC melting features and chain length distributions of lintnerised starches. Carbohyd Res. 1998; 308: 359-371. http://dx.doi.org/10.1016/S0008-6215(98)00100-1

Jane J, Kasemsuwan T, Chen JF, Juliano BO. Phosphorus in rice and other starches. Cereal Food World. 1996; 41(11): 827-832.

Kaur B, Ariffin F, Bhat R, Karim AA. Progress in starch modification in the last decade. Food Hydrocolloid.
2012;

26:

$398-404$

doi:10.1016/j.foodhyd.2011.02.016

Kohajdová Z, Karoviĉová J. Nutritional value and baking applications of spelt wheat. Acta Sci. Pol.Technologia Alimentaria. 2008; 3(7): 5-14.

Lehmann U, Jacobasch G, Schmiedl D. Characterization of resistant starch type III from banana (Musa acuminate). J Agr Food Chem. 2002; 50: 5236-5240. DOI: $10.1021 /$ jf0203390

Lewandowicz G, Jankowski T, Fornal J. Effect of microwave radiation on physico-chemical properties and structure of cereal starches. Carbohyd Polym. 2000; 42: 193-199. http://dx.doi.org/10.1016/S01448617(99)00155-1

Lin PY, Czuchajowska Z. Role of phosphorus in viscosity, gelatinization, and retrogradation of starch. Cereal Chem. 1998; 75(5): 705-709. http://dx.doi.org/10.1094/CCHEM.1998.75.5.705

Liu H, Ramsden L, Corke H. Physical properties of cross-linked and acetylated normal and waxy rice starch. Starch-Starke. 1999; 51: 249-252. http://dx.doi.org/10.1002/(SICI)1521379X(199907)51:7\%3C249::AIDSTAR249\%3E3.0.CO;2-O

Lozoff B, Castillo M, Clark KM, Smith JB. IronFortified vs low iron infant formula. Arch Pedatr Sdolesc Med. 2012; 166(3): 208-215.

http://dx.doi.org/10.1001/archpediatrics.2011.197

Ma J, Betts NM. Zinc and copper intakes and their major food sources for older adults in the 1994-96 Continuing Survey of Food Intakes by Individuals (CSFII). J Nutr. 2000; 130: 2838-2843.

Mezger TG. Rotational tests. In: Zorll U, editor. The rheology handbook: For users of rotational and oscillatory rheometers. Hannover: Vincentz Verlag; 2002. p. 55-68.

Moreira R, Chenlo F, Torres MD, Glazer J. Rheological properties of gelatinized chestnut starch dispersions: Effect of concentration and temperature. J Food Eng. 2012; $\quad$ 112: 94-99. http://dx.doi.org/10.1016/j.jfoodeng.2012.03.021

Morikawa K, Nishinari K. Rheological and DSC studies of gelatinization of chemically modified starch heated at various temperatures. Carbohyd Polym. 2000; 43: 241-247. http://dx.doi.org/10.1016/S01448617(00)00148-X

Nakazawa Y, Wang YJ. Acid hydrolysis of native and annealed starches and branch-structure of their Naegeli dextrins. Carbohyd Res. 2003; 338: 28712882. http://dx.doi.org/10.1016/j.carres.2003.09.005

Pająk P, Fortuna T, Gałkowska D. Rheological characteristics of sour cherries in gels containing waxy maize and cassava starches. J Food Quality. 2012; 35(6): 401-410. http://dx.doi.org/10.1111/jfq. 12005

Pałasiński M. Autohydrolysis of hydrogen starch. Zeszyty Naukowe Wyższej Szkoły Rolniczej w Krakowie, Rozprawy 1968; 39(7): 2-87. 
Przetaczek-Rożnowska I, Rożnowski J, Fortuna T, Szubelak-Iżyk K. Effect of copper ions on selected properties of starch of different botanical origin. Zywn- Nauk Technol Ja. 2012; 2(81): 33-44. Polish http://dx.doi.org/10.15193/zntj/2012/81/033-044

Rajan A, Prasad VS, Abraham TE. Enzymatic esterification of starch using recovered coconut oil. Int J Biol Macromol. 2006; 39: 265-272.

http://dx.doi.org/10.1016/j.ijbiomac.2006.04.006

Richter M, Augustat S, Schierbaum F. Ausgewählte Methoden der Stärkechemie. Starch-Starke. 1968; 20: 277.

Rożnowski J, Fortuna T, Przetaczek-Rożnowska I, Łabanowska M, Bączkowicz M, Kurdziel M et al. Effect of enriching potato and corn starch with Iron ions on selected functional properties. Starch-Starke. 2014; 66: 1049-1059. http://dx.doi.org/10.1002/star.201400070

Rożnowski J, Fortuna T, Szuba E, Labanowska M. Impact of starch phosphorylation and iron(II) and copper(II) ion enrichment on its physicochemical properties. Starch-Starke. 2015; 67: 937-948.

Rożnowski J, Fortuna T, Kłosowska J. Effect of esterification temperature and duration on the physicochemical properties of phosphorylated pelt starch. Journal of Food Process Engineering. 2016a, (in press) http://dx.doi.org/10.1111/jfpe.12365

Rożnowski J, Przetaczek-Rożnowska I, Boba D. Physicochemical properties of native and phosphorylated pumpkin starch. Starch-Starke. 2016b; (in press) http://dx.doi.org/10.1002/star.201500358

Sagar AD, Merrill EW. Properties of fatty-acid ester of starch. J Appl Polym Sci. 1995; 58: 1647-1656. http://dx.doi.org/10.1002/app.1995.070580927
Singh N, Sinngh J, Kaur L, Sodhi NS, Gill BS. Morphological, thermal and rheological properties of starches from different botanical sources. Food Chem. 2003; 81: 219-231. http://dx.doi.org/10.1016/S0308-8146(02)00416-8

Swinkels JJM. Composition and Properties of Commercial Native Starches. Starch-Starke. 1985; 37: 1 ,

$1-5$. http://dx.doi.org/10.1002/star.19850370102

Tester RF, Debon SJJ. Annealing of starch - a review. Int $J$ Biol Macromol. 2000; 27: 1-12. http://dx.doi.org/10.1016/S0141-8130(99)00121-X

Yam KL, Papadakis SE. A simple digital imaging method for measuring and analyzing color of food surfaces. J Food Eng. 2004; 61: 137-142. http://dx.doi.org/10.1016/S0260-8774(03)00195-X

Zimmermann MB, Hurrell RF. Nutritional iron deficiency. Lancet. 2007; 370: 511-520. http://dx.doi.org/10.1016/S0140-6736(07)61235-5

Received: February 02, 2016; Accepted: April 26, 2016 